\title{
INVESTASI DAN PERTUMBUHAN EKONOMI SUMATERA BARAT
}

\author{
Melti Roza Adry \\ Fakultas Ekonomi Universitas Negeri Padang \\ Jl. Prof. Dr. Hamka Air Tawar Padang Sumatera Barat \\ khizahna_zahwa@yahoo.co.id
}

\begin{abstract}
The purpose of the research is to know and analysis causality between invesment and economic growth in West Sumatera. We are using invesment and Economic growth data from $I^{\text {st }}$ quartal 2000 until $4^{\text {th }}$ quartal 2010. We are using unit root test, cointegration test and granger causality test. The result show that investment and economoic growth have causality effect in West Sumatera.
\end{abstract}

Keyword: Invesment, Economic Growth, Unit Root Test, Cointegration Test, Granger Causality Test

\begin{abstract}
Abstrak: Penelitian ini bertujuan untuk melihat hubungan sebab akibat (kausalitas) antara investasi dan Pertumbuhan Ekonomi Sumatera Barat. Data yang digunakan adalah data Investasi dan Pertumbuhan Ekonomi Sumatera Barat Quartal 1 tahun 2000 sampai dengan quartal 4 tahun 2010. Untuk menganalisis data tersebut maka digunakan uji akar unit (unit root test), uji kointegrasi (cointegration test) dan uji granger causality (granger causality test). Hasil analisis menunjukkan bahwa pertumbuhan ekonomi statisoner pada tingkat level sedangkan investasi stationer pada tingkat first different. Uji granger causality menunjukkan adanya hubungan sebab akibat antara investasi dan pertumbuhan ekonomi.
\end{abstract}

Kata Kunci: Investasi, Pertumbuhan Ekonomi, Unit Root Test, Cointegration Test, Granger Causality Test

Teori pertumbuhan Harrod-Domar (Jingan 2000) menyatakan bahwa kegiatan investasi akan menimbulkan efek langsung terhadap pengeluaran aggregat dan kapasitas produksi. Efek langsung dari pengeluaran investasi terjadi pada sisi permintaan agregat bila pengeluaran investasi meningkat, yang kemudian akan meningkatkan pendapatan nasional/daerah melalui proses multiplier. Efek terhadap kapasitas produksi, yaitu efek dari pengeluaran investasi terjadi pada sisi penawaran agregat yang lebih besifat jangka panjang di mana kenaikan pengeluaran investasi akan menaikkan jumlah kapital. Dengan jumlah kapital yang meningkat, kapasitas produksi perekonomian akan meningkat yang kemudian akan meningkatkan penawaran agregat. Selain itu, untuk meningkatkan investasi perlu ditunjang oleh tingkat pertumbuhan ekonomi sebagai representasi dari kondisi perekonomian suatu daerah. 
Sumatera Barat sebagai salah satu propinsi di Indonesia, masih mengalami kendala baik dari sisi investasi maupun pertumbuhan ekonomi. Sektor investasi di Sumatera Barat masih mengalami kendala-kendala seperti keamanan, kepastian hukum, dan masalah perburuhan sehingga banyak investorinvestor yang melarikan modalnya ke luar negeri dan melakukan relokasi tempat usaha oleh beberapa perusahaan dan investor.

Tabel 1. Pertumbuhan Ekonomi, dan Investasi Propinsi Sumatera Barat Atas Dasar Harga Konstan 2000 menurut penggunaan (periode 2001-2010).

\begin{tabular}{ccccc}
\hline \multirow{2}{*}{ Tahun } & \multicolumn{2}{c}{ PDRB } & \multicolumn{2}{c}{ Investasi } \\
\cline { 2 - 5 } & $\begin{array}{c}\text { PDRB } \\
\text { (Juta Rp) }\end{array}$ & $\begin{array}{c}\text { Pertumbuhan Ekonomi } \\
(\boldsymbol{\%})\end{array}$ & Investasi & $\begin{array}{c}\text { Pertumbuhan Investasi } \\
(\boldsymbol{\%})\end{array}$ \\
\hline 2001 & 23.727 .373 & - & 4.736 .135 & - \\
2002 & 24.840 .188 & 4.69 & 4.785 .540 & 1.04 \\
2003 & 26.146 .781 & 5.26 & 4.934 .281 & 3.11 \\
2004 & 27.578 .137 & 5.47 & 5.091 .190 & 3.18 \\
2005 & 29.159 .481 & 5.73 & 5.388 .134 & 5.83 \\
2006 & 30.949 .395 & 6.14 & 5.604 .646 & 4.02 \\
2007 & 32.912 .970 & 6.34 & 5.824 .273 & 3.92 \\
2008 & 35.007 .922 & 6.37 & 6.112 .929 & 4.96 \\
2009 & 36.683 .239 & 4.79 & 6.569 .621 & 7.47 \\
2010 & 38.869 .164 & 5.96 & 6.643 .190 & 1.12 \\
\hline Sumber : BPS Sumatera Barat 2011. & & &
\end{tabular}

Tabel 1 terlihat bahwa pertumbuhan ekonomi di Propinsi Sumatera Barat sejak periode 2001 - 2010 cenderung meningkat. Hal ini dipengaruhi oleh perkembangan investasi yang juga cenderung mengalami peningkatan. Perubahan tersebut mampu mendorong laju pertumbuhan ekonomi Sumatera Barat ke depan. Begitupun sebaliknya peningkatan pertumbuhan ekonomi berimbas terhadap peningkatan investasi. Namun pada tahun 2009 penurunan pertumbuhan ekonomi tidak berimbas terhadap penurunan investasi Sumatera Barat.

Pertumbuhan ekonomi Sumatera Barat tertinggi berada pada tahun 2008 sebesar $6,37 \%$. Hal ini cenderung dipengaruhi oleh meningkatnya perubahan investasi. Selanjutnya pertumbuhan ekonomi Sumatera Barat terendah berada pada tahun 2002. Rendahnya pertumbuhan ekonomi pada tahun tersebut disebabkan sedikitnya investasi yang masuk ke Sumatera Barat. Dengan demikian maka terlihat bahwa adanya keterkaian antara investasi dan pertumbuhan ekonomi di Sumatera Barat.

Tulisan ini bertujuan untuk mengetahui apakah terdapat hubungan kausalitas antara investasi dan pertumbuhan ekonomi di Sumatera Barat dengan menggunakan pendekatan kausalitas granger. Sehingga, dengan pendekatan ini terlihat apakah benar terdapat hubungan kausalitas antara investasi dan pertumbuhan ekonomi di Sumatera Barat. 


\section{TINJAUAN LITERATUR}

Harrod-Domar (Jhingan, 2000) menyatakan bahwa kegiatan investasi akan menimbulkan dua efek, yaitu efek langsung terhadap pengeluaran aggregat dan efek terhadap kapasitas produksi. Efek langsung dari pengeluaran investasi terjadi pada sisi permintaan agregat bila pengeluaran investasi meningkat, yang kemudian akan meningkatkan pendapatan nasional/daerah melalui proses multiplier. Efek terhadap kapasitas produksi, yaitu efek dari pengeluaran investasi terjadi pada sisi penawaran agregat yang lebih besifat jangka panjang di mana kenaikan pengeluaran investasi akan menaikkan jumlah kapital. Dengan jumlah kapital yang meningkat, kapasitas produksi perekonomian akan meningkat yang kemudian akan meningkatkan penawaran agregat.

Selanjutnya menurut Teori pertumbuhan endogen (Mankiw, 2003) yang dimulai dengan fungsi produksi bahwa

$\mathrm{Y}=\mathrm{AK}$

Dimana $\mathrm{Y}$ adalah output, $\mathrm{K}$ adalah persedian modal dan A adalah konstanta yang mengukur jumlah output yang diproduksi untuk setiap unit modal. Fungsi produksi ini tidak menunjukkan muatan dari dari pengembalian modal yang kian menurun. Satu unit modal tambahan memproduksi inut output tambahan sebesar A, tanpa memperhitungkan berapa banyak modal yang ada.

Selanjutnya, dengan mengasumsikan bahwa sebagian pendapatan ditabung dan diinvestasikan, maka akumulasi modal:

$\Delta \mathrm{K}=\mathrm{sY}-\Delta \mathrm{k}$

Persamaan ini menyatakan bahwa perubahan persediaan modal $(\Delta K)$ sama dengan investasi $(\mathrm{sY})$ dikurangi depresiasi $(\delta \mathrm{K})$. Menggan=bungkan persamaan tersebut dengan fungsi produksi $\mathrm{Y}=\mathrm{AK}$, diperoleh,

$\frac{\Delta Y}{Y}=\frac{\Delta K}{K}=s A-\delta$

Berdasarkan persamaan di atas terlihat jelaslah apa yang mempengaruhi tingkat pertumbuhan output $\left(\frac{\Delta Y}{Y}\right)$. Selama $s A>\delta$, pendapatan perekonomian tumbuh selamanya, meskipun tanpa asumsi kemajuan teknologi eksogen.

Selanjutnya, Mankiw (2003) menyatakan bahwa fungsi investasi memberikan gambaran tentang sifat hubungan diantara tingkat investasi dengan tingkat pendapatan nasional. Perubahan dalam investasi akan menimbulkan perubahan dalam pembelanjaan agregat dan keseimbangan pendapatan nasional.

Kegiatan investasi memungkinkan suatu masyarakat terus menerus meningkatkan kegiatan perekonomian dan kesempatan kerja, meningkatkan pendapatan nasional dan meningkatkan taraf kemakmuran masyarakat. Dengan demikian, terlihat bahwa: (1). Investasi merupakan salah satu komponen dari pengeluaran agregat. Maka kenaikan investasi akan meningkatkan permintaan agregat dan pendapatan nasional. (2) Pertambahan barang modal sebagai akibat 
investasi akan menambahkan kapasitas memproduksi dimasa depan dan perkembangan ini akan menstimulir pertambahan produksi nasional dan kesempatan kerja. (3). Investasi selalu diikuti oleh perkembangan teknologi. Perkembangan ini akan memberikan sumbangan penting ke atas kenaikan produktivitas dan pendapatan perkapita masyarakat.

Sesuai dengan pandangan teori akselerasi, berpendapat bahwa pendapatan nasional yang semakin meningkat akan memerlukan barang modal yang semakin banyak. Dengan demikian perusahaan perlu melakukan investasi yang lebih tinggi dan lebih banyak modal yang dipinjam.

Berdasarkan pendapat di atas disimpulkan bahwa tingkat investasi ditentukan oleh pertumbuhan ekonomi dan sebaliknya pertumbuhan ekonomi juga ditentukan oleh tingkat investasi. Kenaikan investasi akan memicu peningkatan pertumbuhan ekonomi dan pertumbuhan ekonomi yang tinggi akan memicu minat berinvestasi.

\section{METODE PENELITIAN}

Untuk menganalisis digunakan data investasi dan pertumbuhan ekonomi Sumatera Barat atas dasar harga konstan tahun 2000, kuartal 1 tahun 2000 sampai dengan kuartal 4 tahun 2010 digunakan model Granger Causality. Model ini dapat digunakan secara khusus untuk menguji arah sebab akibat dari hubungan ekonomi. Model yang digunakan adalah:

$$
\begin{aligned}
& Y_{1 t}=\beta_{10}+\beta_{11} Y_{1 t-1}+\cdots+\beta_{1 p} Y_{1 t-p}+\alpha_{11} Y_{2 t-1}+\cdots+\alpha_{1 p} Y_{2 t-p}+U_{1 t} \\
& Y_{2 t}=\beta_{20}+\beta_{21} Y_{2 t-1}+\cdots+\beta_{2 p} Y_{1 t-p}+\alpha_{21} Y_{1 t-1}+\cdots+\alpha_{2 p} Y_{1 t-p}+U_{2 t}
\end{aligned}
$$

Menurut Sarwoko (2005) untuk melihat ada tidaknya arah sebab akibat digunakan rumus sebagai berikut:

$F=\frac{\left.R S S_{R}-R S S_{U R}\right) / m}{\left.R S S_{U R}\right) / n-k}$

dimana $\mathrm{m}$ adalah jumlah lag perlambanan, $\mathrm{k}$ adalah jumlah estimasi parameter pada regresi yang tidak direstriksi. Dengan kriteria:

$F$ hitung $>F$ tab dengan $\alpha=0,05$ atau prob $<\alpha=0,05$ maka ho ditolak

$\mathrm{F}$ hitung $<\mathrm{F}$ tab dengan $\alpha=0,05$ atau prob $>\alpha=0,05$ maka ho diterima

\section{HASIL DAN PEMBAHASAN}

Uji stasioner yang digunakan dalam penelitian ini adalah uji akar unit (unit root test) yang dikembangkan oleh David Dickey dan Wayne Fuller, atau yang lebih dikenal dengan uji akar unit Dickey-Fuller (DF). Hasil analisis stationer menunjukkan bahwa investasi stationer pada tingkat first different sedangkan pertumbuhan ekonomi pada tingkat level. Namun demikian, untuk menganalisis maka penulis menyamakan menjadi first different (lampiran 1 dan 2) seperti terlihat pada Tabel 2. Jadi berdasarkan uji stationer di atas diperoleh kesimpulan adalah data yang dianalisis bersifat randomness. 
Tabel 2. Uji Stasioneritas

\begin{tabular}{lll}
\hline Nama Variabel & Tingkat & Nilai Probabilitas \\
\hline Perekonomian (Y) & Level & 0.0000 \\
Investasi (I) & $I^{\text {st }}$ difference & 0.0000 \\
\hline
\end{tabular}

Sumber: Data Olahan, 2011

Selanjutnya berdasarkan uji kointegrasi Johansen ditemukan bahwa investasi dan pertumbuhan ekonomi dalam periode analisis memiliki hubungan jangka panjang dengan nilai probabilitas 0.0117 .

Tabel 3. Pairwise Granger Causality Tests

\begin{tabular}{lccc}
\hline Null Hypothesis: & Obs & F-Statistic & Prob. \\
\hline & & & \\
D(Y) does not Granger Cause D(LOG(I)) & 41 & 2.58902 & 0.0890 \\
D(LOG(I)) does not Granger Cause D(Y) & & 19.6994 & $2 . E-06$
\end{tabular}

Sumber; Data Olahan, 2011

Berdasarkan hasil uji kausalitas granger menunjukkan bahwa investasi dan pertumbuhan ekonomi memiliki hubungan kausalitas, $\mathrm{D}(\mathrm{Y})$ does not Granger Cause $\mathrm{D}(\mathrm{LOG}(\mathrm{I}))$ dan $\mathrm{D}(\mathrm{LOG}(\mathrm{I})$ ) does not Granger Cause $\mathrm{D}(\mathrm{Y})$ dengan probabilitas kecil dari $\alpha=0,10$ sehingga dapat disimpulkan bahwa terdapat hubungan kausalitas antara pertumbuhan ekonomi dan investasi di Sumatera Barat.

\section{SIMPULAN}

Hasil penelitian menunjukkan bahwa terdapat hubungan jangka panjang antara investasi dan pertumbuhan ekonomi Sumatera Barat dan terdapatnya hubungan kausalitas antara investasi dan pertumbuhan ekonomi Sumatera Barat. Berdasarkan hasil penelitian tersebut maka terlihat perlunya menjaga kestabilan pertumbuhan ekonomi sehingga mampu meningkatkan investasi di Sumatera Barat. Selain itu, juga diperlukan peranan investasi untuk meningkatkan pertumbuhan ekonomi Sumatera Barat, sehingga akan terbuka lapangan usaha dalam artian pengurangan angka penganggguran di Sumatera Barat. Kegiatan investasi memungkinkan suatu masyarakat terus menerus meningkatkan kegiatan perekonomian dan kesempatan kerja, meningkatkan pendapatan nasional dan meningkatkan taraf kemakmuran masyarakat. Dengan demikian, bahwa: (1). Kenaikan investasi akan meningkatkan permintaan agregat dan pendapatan nasional. (2) Pertambahan barang modal sebagai akibat investasi akan menambahkan kapasitas memproduksi dimasa depan dan perkembangan ini akan menstimulir pertambahan produksi nasional dan kesempatan kerja. (3). Investasi selalu diikuti oleh perkembangan teknologi. Perkembangan ini akan memberikan 
sumbangan penting ke atas kenaikan produktivitas dan pendapatan perkapita masyarakat.

\section{LAMPIRAN}

\section{Tabel L-1. Uji Stationer Investasi Pada Tingkat Level}

Null Hypothesis: LOG(I) has a unit root

Exogenous: Constant

Lag Length: 3 (Automatic based on SIC, MAXLAG=9)

\begin{tabular}{lccc}
\hline \hline & t-Statistic & Prob.* \\
\hline \hline Augmented Dickey-Fuller test statistic & -0.276501 & 0.9195 \\
\hline Test critical values: & $1 \%$ level & -3.605593 & \\
& $5 \%$ level & -2.936942 & \\
& $10 \%$ level & -2.606857 & \\
\hline \hline
\end{tabular}

*MacKinnon (1996) one-sided p-values.

Augmented Dickey-Fuller Test Equation

Dependent Variable: D(LOG(I))

Method: Least Squares

Date: 10/25/12 Time: 00:23

Sample (adjusted): 2001Q1 2010Q4

Included observations: 40 after adjustments

\begin{tabular}{lrlrr}
\hline \hline \multicolumn{1}{c}{ Variable } & Coefficient & Std. Error & t-Statistic & Prob. \\
\hline \hline \multicolumn{1}{c}{ LOG(I(-1)) } & -0.026167 & 0.094635 & -0.276501 & 0.7838 \\
D(LOG(I(-1))) & -0.526592 & 0.157440 & -3.344716 & 0.0020 \\
D(LOG(I(-2))) & -0.459826 & 0.164726 & -2.791465 & 0.0084 \\
D(LOG(I(-3))) & -0.572483 & 0.148884 & -3.845171 & 0.0005 \\
\multicolumn{1}{c}{ C } & 0.391303 & 1.335678 & 0.292962 & 0.7713 \\
\hline \hline & 0.430458 & Mean dependent var & & 0.007371 \\
R-squared & 0.365367 & S.D. dependent var & & 0.085305 \\
Adjusted R-squared & 0.067958 & Akaike info criterion & & -2.423397 \\
S.E. of regression & 0.161638 & Schwarz criterion & & -2.212287 \\
Sum squared resid & 53.46794 & Hannan-Quinn criter. & & -2.347066 \\
Log likelihood & 6.613210 & Durbin-Watson stat & & 2.259044 \\
F-statistic & 0.000450 & & \\
Prob(F-statistic) & & & \\
\hline \hline
\end{tabular}


Tabel L - 2. Uji Stasioner Investasi Pada Tingkat First Different

Null Hypothesis: D(LOG(I)) has a unit root

Exogenous: Constant

Lag Length: 2 (Automatic based on SIC, MAXLAG=9)

\begin{tabular}{|c|c|c|c|}
\hline & & t-Statistic & Prob.* \\
\hline \multicolumn{2}{|c|}{ Augmented Dickey-Fuller test statistic } & -8.061980 & 0.0000 \\
\hline \multirow[t]{3}{*}{ Test critical values: } & $1 \%$ level & -3.605593 & \\
\hline & $5 \%$ level & -2.936942 & \\
\hline & $10 \%$ level & -2.606857 & \\
\hline
\end{tabular}

*MacKinnon (1996) one-sided p-values.

Augmented Dickey-Fuller Test Equation

Dependent Variable: D(LOG(I),2)

Method: Least Squares

Date: 10/25/12 Time: 00:24

Sample (adjusted): 2001Q1 2010Q4

Included observations: 40 after adjustments

\begin{tabular}{lrlrr}
\hline \hline \multicolumn{1}{c}{ Variable } & Coefficient & Std. Error & t-Statistic & Prob. \\
\hline \hline D(LOG(I(-1))) & -2.607323 & 0.323410 & -8.061980 & 0.0000 \\
D(LOG(I(-1)),2) & 1.060830 & 0.244647 & 4.336161 & 0.0001 \\
D(LOG(I(-2)),2) & 0.583812 & 0.141287 & 4.132116 & 0.0002 \\
\multicolumn{1}{c}{ C } & 0.022000 & 0.011020 & 1.996246 & 0.0535 \\
\hline \hline R-squared & 0.787039 & Mean dependent var & -0.000294 \\
Adjusted R-squared & 0.769292 & S.D. dependent var & 0.139657 \\
S.E. of regression & 0.067080 & Akaike info criterion & -2.471215 \\
Sum squared resid & 0.161991 & Schwarz criterion & -2.302327 \\
Log likelihood & 53.42430 & Hannan-Quinn criter. & -2.410150 \\
F-statistic & 44.34832 & Durbin-Watson stat & 2.270196 \\
Prob(F-statistic) & 0.000000 & & & \\
\hline \hline
\end{tabular}




\section{Tabel L-3. Uji Stasioner Pertumbuhan Ekonomi Pada tingkat Level}

Null Hypothesis: Y has a unit root

Exogenous: Constant

Lag Length: 0 (Automatic based on SIC, MAXLAG=9)

\begin{tabular}{lccc}
\hline \hline & t-Statistic & Prob.* \\
\hline \hline Augmented Dickey-Fuller test statistic & -7.983247 & 0.0000 \\
\hline Test critical values: & $1 \%$ level & -3.592462 & \\
& $5 \%$ level & -2.931404 & \\
$10 \%$ level & -2.603944 & \\
\hline \hline
\end{tabular}

*MacKinnon (1996) one-sided p-values.

Augmented Dickey-Fuller Test Equation

Dependent Variable: D(Y)

Method: Least Squares

Date: 10/25/12 Time: 00:26

Sample (adjusted): 2000Q2 2010Q4

Included observations: 43 after adjustments

\begin{tabular}{lrlrr}
\hline \hline \multicolumn{1}{c}{ Variable } & Coefficient & \multicolumn{1}{c}{ Std. Error } & t-Statistic & Prob. \\
\hline \multicolumn{1}{c}{ Y(-1) } & -1.220772 & 0.152917 & -7.983247 & 0.0000 \\
\multicolumn{1}{c}{1.651238} & 0.235569 & 7.009575 & 0.0000 \\
\hline \hline R-squared & 0.608526 & Mean dependent var & & 0.017674 \\
Adjusted R-squared & 0.598977 & S.D. dependent var & 1.208555 \\
S.E. of regression & 0.765333 & Akaike info criterion & & 2.348385 \\
Sum squared resid & 24.01515 & Schwarz criterion & & 2.430301 \\
Log likelihood & -48.49028 & Hannan-Quinn criter. & & 2.378593 \\
F-statistic & 63.73224 & Durbin-Watson stat & & 1.885203 \\
Prob(F-statistic) & 0.000000 & & \\
\hline \hline
\end{tabular}


Tabel L- 4. Uji Stasioner Pertumbuhan Ekonomi Pada tingkat First Different

Null Hypothesis: D(Y) has a unit root

Exogenous: Constant

Lag Length: 5 (Automatic based on SIC, MAXLAG=9)

\begin{tabular}{lccc}
\hline \hline & t-Statistic & Prob.* \\
\hline \hline Augmented Dickey-Fuller test statistic & -4.226953 & 0.0020 \\
\hline Test critical values: & 1\% level & -3.621023 & \\
& 5\% level & -2.943427 & \\
$10 \%$ level & -2.610263 & \\
\hline \hline
\end{tabular}

*MacKinnon (1996) one-sided p-values.

Augmented Dickey-Fuller Test Equation

Dependent Variable: $\mathrm{D}(\mathrm{Y}, 2)$

Method: Least Squares

Date: 10/25/12 Time: 00:26

Sample (adjusted): 2001Q4 2010Q4

Included observations: 37 after adjustments

\begin{tabular}{crlrr}
\hline \hline Variable & Coefficient & Std. Error & t-Statistic & Prob. \\
\hline \hline $\mathrm{D}(\mathrm{Y}(-1))$ & -10.53889 & 2.493260 & -4.226953 & 0.0002 \\
$\mathrm{D}(\mathrm{Y}(-1), 2)$ & 8.438582 & 2.455752 & 3.436252 & 0.0017 \\
$\mathrm{D}(\mathrm{Y}(-2), 2)$ & 8.115424 & 2.606003 & 3.114127 & 0.0040 \\
$\mathrm{D}(\mathrm{Y}(-3), 2)$ & 8.412663 & 3.046731 & 2.761209 & 0.0097 \\
$\mathrm{D}(\mathrm{Y}(-4), 2)$ & 8.063464 & 3.019468 & 2.670492 & 0.0121 \\
$\mathrm{D}(\mathrm{Y}(-5), 2)$ & 4.982885 & 2.006935 & 2.482833 & 0.0189 \\
\multicolumn{1}{c}{$\mathrm{C}$} & 0.160876 & 0.135352 & 1.188571 & 0.2439 \\
\hline \hline & 0.908785 & Mean dependent var & & -0.044324 \\
R-squared & 0.890542 & S.D. dependent var & & 2.389266 \\
Adjusted R-squared & 0.790477 & Akaike info criterion & & 2.536297 \\
S.E. of regression & 18.74561 & Schwarz criterion & & 2.841065 \\
Sum squared resid & -39.92150 & Hannan-Quinn criter. & & 2.643742 \\
Log likelihood & 49.81532 & Durbin-Watson stat & & 2.118295 \\
F-statistic & 0.000000 & & \\
Prob(F-statistic) & & & & \\
\hline \hline
\end{tabular}




\section{Tabel L- 5. Uji Kointegrasi}

Date: 10/25/12 Time: 00:33

Sample (adjusted): 2000Q3 2010Q4

Included observations: 42 after adjustments

Trend assumption: Linear deterministic trend

Series: I Y

Lags interval (in first differences): 1 to 1

Unrestricted Cointegration Rank Test (Trace)

\begin{tabular}{|c|c|c|c|c|}
\hline $\begin{array}{c}\text { Hypothesized } \\
\text { No. of CE(s) }\end{array}$ & Eigenvalue & $\begin{array}{c}\text { Trace } \\
\text { Statistic }\end{array}$ & $\begin{array}{c}0.05 \\
\text { Critical Value }\end{array}$ & Prob.** \\
\hline None ${ }^{*}$ & 0.315466 & 19.52672 & 15.49471 & 0.0117 \\
\hline At most 1 & 0.082319 & 3.608014 & 3.841466 & 0.0575 \\
\hline
\end{tabular}

Trace test indicates 1 cointegrating eqn(s) at the 0.05 level

$*$ denotes rejection of the hypothesis at the 0.05 level

**MacKinnon-Haug-Michelis (1999) p-values

Unrestricted Cointegration Rank Test (Maximum Eigenvalue)

\begin{tabular}{|c|c|c|c|c|}
\hline $\begin{array}{l}\text { Hypothesized } \\
\text { No. of CE(s) }\end{array}$ & Eigenvalue & $\begin{array}{l}\text { Max-Eigen } \\
\text { Statistic }\end{array}$ & $\begin{array}{c}0.05 \\
\text { Critical Value }\end{array}$ & Prob.** \\
\hline None * & 0.315466 & 15.91871 & 14.26460 & 0.0271 \\
\hline At most 1 & 0.082319 & 3.608014 & 3.841466 & 0.0575 \\
\hline
\end{tabular}

Max-eigenvalue test indicates 1 cointegrating eqn(s) at the 0.05 level

* denotes rejection of the hypothesis at the 0.05 level

**MacKinnon-Haug-Michelis (1999) p-values

Unrestricted Cointegrating Coefficients (normalized by $b^{\prime *} \mathrm{~S} 11 * \mathrm{~b}=\mathrm{I}$ ):

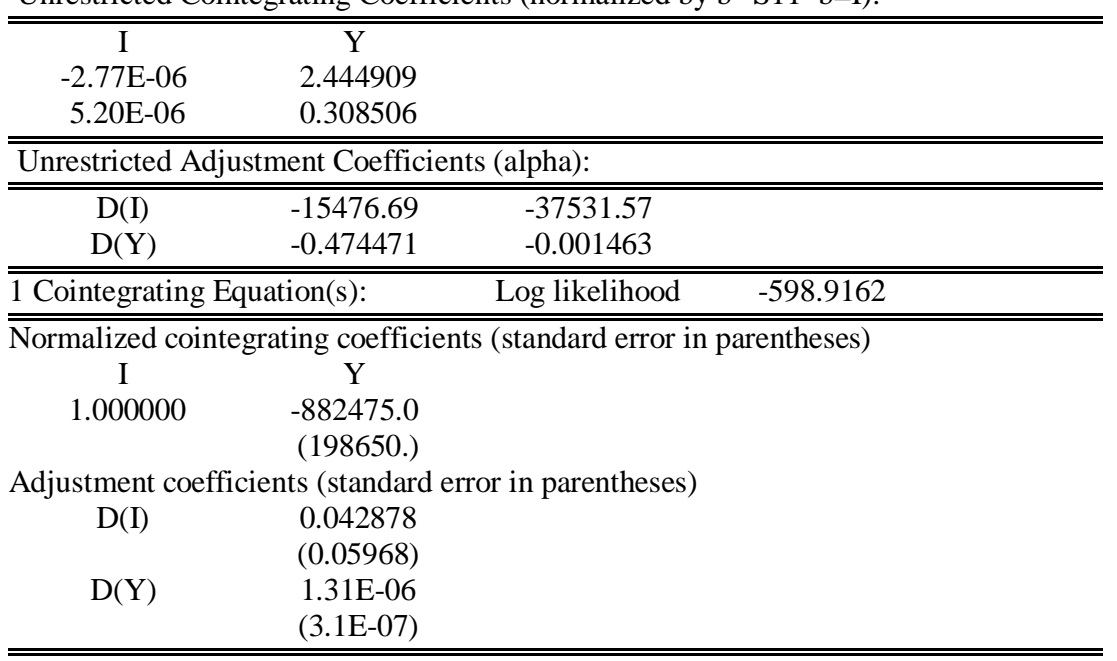




\section{Tabel L- 6. Uji Kausalitas Granger}

Pairwise Granger Causality Tests

Date: 10/25/12 Time: 00:28

Sample: 2000Q1 2010Q4

Lags: 2

\begin{tabular}{lccr}
\hline \hline Null Hypothesis: & Obs & F-Statistic & Prob. \\
\hline \hline D(Y) does not Granger Cause D(LOG(I)) & 41 & $\begin{array}{l}2.58902 \\
19.6994\end{array}$ & $\begin{array}{l}0.0890 \\
2 . E-06\end{array}$ \\
D(LOG(I)) does not Granger Cause D(Y) & & & \\
\hline \hline
\end{tabular}

\section{DAFTAR RUJUKAN}

Agenor, Pierre Richard \& Peter J. Montiel. (2008). Development Microeconomic $3^{\text {th }}$ edition. Princeton University Press: United Kingdom.

Asngari, Imam. Keseimbangan Pendapatan Nasional Dan Kebijakan Fiskal. www.google.com. Diakses 20 Mei 2010.

Bank Indonesia. (2000 - 2010). Kinerja Ekonomi Regional Sumbar. BI, Padang. . (2010). Tinjauan Ekonomi Regional triwulan I. BI: Jakarta.

\section{Padang.} (2000-2010). Statistik Ekonomi dan Keuangan Daerah. BI

Devie. (2000). Tinjauan atas suku bunga dan dampaknya Pada keputusan investasi dan pembiayaan. Jurnal Akuntansi \& Keuangan Vol. 2, No. 2, Nopember 2000: 162 - 173

Dornbusch, Rudiger. (2008). Makroekonomi. MGE, Washington. . (2004). Macroeconomics. International Edition. Ninth Edition: Mc Graw Hill.

Gujarati, Damodar. (2003). Basic Econometrics (4 ${ }^{\text {th }}$ edition). Mc. Graw Hill. Singapore.

Greene, William H. (2003). Econometric Analysis (5 $5^{\text {th }}$ edition). Prentice Hall. New York.

Hadi, Yonathan S. (2003). Analisis vector auto regression (var) terhadap korelasi antara pendapatan nasional dan investasi pemerintah di indonesia, 1983/1984 - 1999/2000. Jurnal Keuangan dan Moneter, Volume 6 Nomor 2 Desember 2003.

Jhingan, M.L (2007). Ekonomi Pembangunan dan Perencanaan. Jakarta: Rajawali Pers.

Kustituanto, Bambang dan Istikomah (1999), Peranan Penanaman Modal Asing terhadap Pertumbuhan Ekonomi, JEBI, Volume 14, No. 2, Yogyakarta.

Mankiw, Gregory N. (2003), Teori Makro Ekonomi, Erlangga: Jakarta.

Meyer, H Laurence (1980). Macroeconomic, A Model Building Approach. SouthWestern Publishing Co: Chicago.

Nachrowi, Nachrowi D. (2006). Pendekatan Populer dan Praktis Ekonometrika Untuk Analisis Ekonomi dan Keuangan. FE UI: Jakarta. 
Nellis, Josepg G. (2000). The Essence of The Economy. Prentice Hall Internasional: UK.

Ramanathan, Ramu. (1998). Introductory Econometrics With Application (4 $^{\text {th }}$ edition). George Provol: Califonia.

Ratnawati, Nirdukita dan Rulli Rizki (2007)Analisis pengaruh variabel indikator ekonomi makro terhadap perekonomian Indonesia: pendekatan pasar barang dan pasar uang (jurnal) periode 1990.1-2005.4. Jurnal Ekonomi Indonesia No. 2 Desember 2007.

Romer, David. (2005). Advanced Macroeconomics. The McGraw-Hill Companies, Inc: New York.

Sarwoko. (2005). Dasar-Dasar Ekonometrika. Yokyakarta: Andi.

Sumodiningrat, Gunawan. (2007). Ekonometrika Pengantar. BPFE: Yokyakarta.

Todaro, Michael, P. (2000). Pembangunan Ekonomi di Dunia Ketiga, Alih Bahasa Indonesia: Burhanudin Abdullah dan Harris Munandar. Erlangga: Jakarta.

( 2000). Economic Development, $7^{\text {th }}$ Editions. New York: Addition Wesley Longman, Inc.

Walsh, Carl E. (2010). Monetary Theory and Policy Third Edition. The MIT Press: Cambridge Massachusetts.

Yuliandi, Imanuddin. (2001). Analisis Makro Ekonomi Pendekatan IS-LM. Jurnal Ekonomi Pembangunan, Kajian Ekonomi Negara Berkembang Vol 6 No.2 2001. 